Vet. Serum and Vaccine Research Institute, Abbasia, Cairo.

\title{
TRIALS OF USING CELI, CULTURES FOR EVALUATION OF IBDV VACCINES IN EGYPT
}

(With 5 Tables and One Figure)

\section{By \\ ELHAM, A. EL-EBIARY; SUSAN, S. EL-MAHDY and M.H. KHODEIR}

(Received at 12/5/1996)

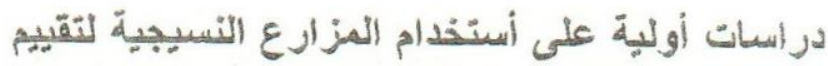

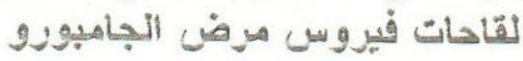

اليهام الأبيارى ، سنزان المهلى ، محسد خضير

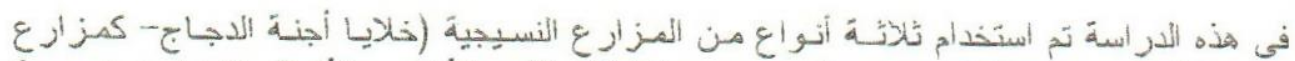

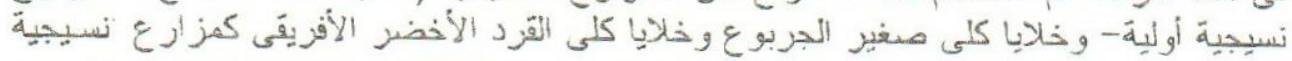

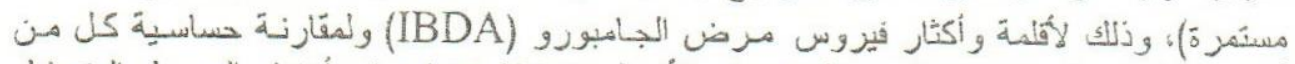

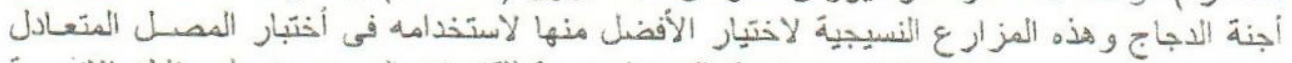

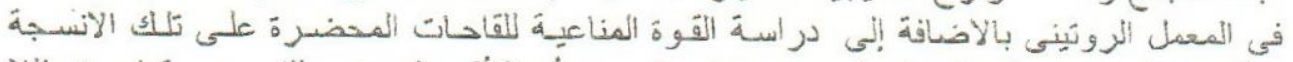

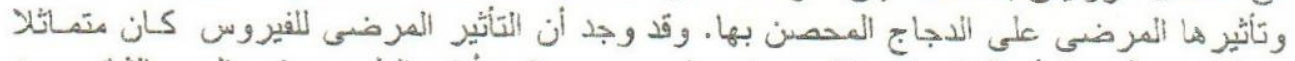

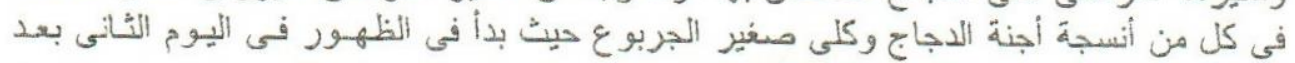

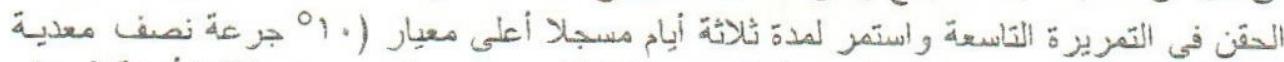

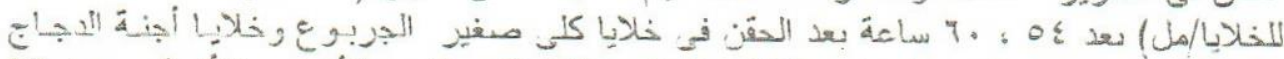

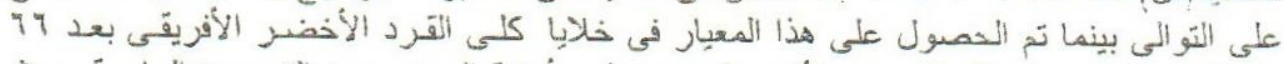

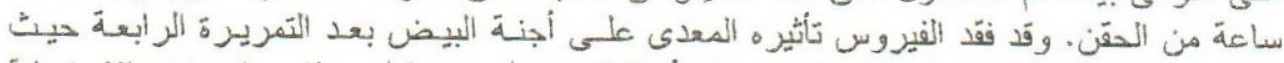

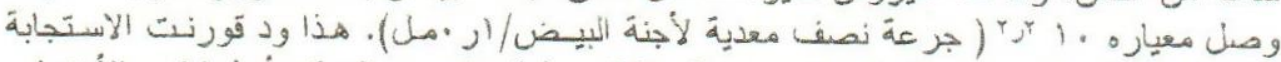

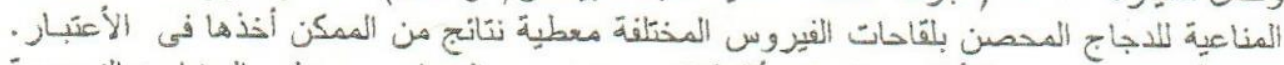

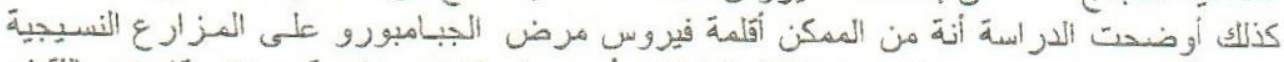

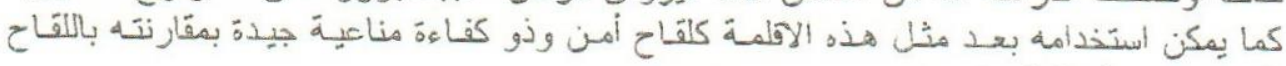

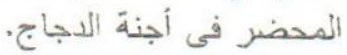




\section{SUMMARY}

Three cell cultures were used in this work to propagate and replicate the infectious bursal disease virus (IBDV), (primary chicken embryo fibroblast cells "CEF" and two cell lines, African green monkey kidney cells (VERO) and baby hamster kidney cell (BHK) and compare their sensitivity to that of embryonated chicken eggs in order to use the selected cell culture adapted IBDV in the routine serum neutralization test (SNT) and evaluate its immunogenicity and pathogenicity in chicken. It was found that: 1- The cytopathic effect (CPE) of the IBDV in CEF and BHK was similar where it began to be pronounced after 9 passages at 2 days post inoculation (PI) and took 3 days in both cell culture. The cell culture adapted IBDV lost its infectivity to the embryonated chicken egg at the passage No. 5 as after the passage No. 2 the EID50 was $10^{2.2}$ per $0.1 \mathrm{ml}$. The peak virus titre $\left(10^{5}\right.$ TCID50 / $0.1 \mathrm{ml}$ ) was detected at 54 and 60 hours post inoculation in BHK and CEF respectively, while the virus titre in VERO cells reached a plateau $10^{5} \mathrm{TCID} 50 / 0.1 \mathrm{ml}$ at 60 hours PI. 2- The detection of the level of antibody titre in the sera of vaccinated chicken, using the microtitre neutralization test and embryonated chicken eggs (ECE) revealed comparable results. 3- These preliminary studies indicated that the cell culture adapted IBDV could be used safely as a vaccinal strain in the production of cell culture vaccine, as it gave a good immunity when compared with the egg adapted imported vaccine.

\section{Key words: IBDV-vaccines - cell culture - Egypt}

\section{INTRODUCTION}

Infectious bursal disease virus has been adapted to replicate and produce cytopathic effect (CPE) in various primary cell cultures from chicken embryo origin (CEF) (Petek and Mandelli, 1968; Gelenczei and Juniger, 1970), in turkey embryo fibroblast (TEF) and in duck embryo fibroblast (DEF) (McNulty et at., 1979).

Much works have been done on virus grown in embryonated chicken eggs (Benton et at., 1967; Kosterset et at., 1972 and Winterfield, 1969).

Some workers have characterized the growth of IBDV in cell cultures from the bursa of Fabricius and chicken embryo kidney (CEK) (Lukert and Davis, 1974) and in primary cultures of macrophages and 
lymphocytes (Mora, 1966). Few researches have reported growth of IBDV in mammalian continuous cell lines (Rinaldi et at., 1972 and Petek et at., 1973). Such cell lines were derived from rabbit kidney cells (RK-13). Lukert et at. (1975) adapted IBDV to VERO cells.

Several vaccines have been developed and some of them have been shown to produce mild form of the disease causing an effect on the bursa of Fabricius that can lead to immuno - suppression (Winterfield, 1969).

The objective of the present study is to search for the suitable cell culture specially the continuous cell line to adapte the IBDV to replicate and produce CPE for use in routine virus neutralization test (VNT) for evaluation of different IBDV vaccines which have performed in embryonated chicken eggs as this method is specific and sensitive but it is more time consuming and less economic since it requires large number of embryonated chicken eggs. Also, to investigate the possibility of using this adapted cell culture strain in immunological trials to could be used as a cell culture vaccine.

\section{MATERIAL and METHODS}

\section{(A) Material:}

\section{IBD viruses:}

\subsection{Viruses used for SNT:}

An attenuated egg adapted IBDV strain was obtained from Animal Health Research Institute, Dept. of Immun. Its titre was $108 \mathrm{EID} 50 / \mathrm{ml}$. It used for the propagation in different cell cultures and immunological experiments in chicken.

\subsection{Virulent IBDV :}

It was isolated from the bursa of Fabricius of IBDV infected chickens. Its titre was $108 \mathrm{EID} 50 / \mathrm{ml}$. It was given to chicken as a challenge virus via
the eye drop route as a dose of 50 EID 50 .

\subsection{Vaccines :}

Six types of commercial inactivated and live vaccines were supplied by different companies and were designated as follows:

\subsubsection{Inactivated vaccines :}

a.Variant strains of IBDV (Baxendale type 1; Manryland type 1; Delware 1084 and 1084 E type 1). They were obtained by MBL Company, Lot
No. 3916 . 
b. Winterfield 2512 strain (produced by MBL Lot No. 4901).

c. Intervet strain (produced by Intervet, Lot No. 49031).

d. Gumboro D78 (produced by Intervet International, Boxmeer, Holland, Lot No. 49039).

\subsubsection{Live vaccines :}

Strain D78 vaccine (produced by Intervet) with a titre of $10^{6.5}$ EID50/ $\mathrm{ml}$. These vaccines were used for experimental vaccination of chicken as the routine evaluation of them.

2. Newcastle disease viruses (NDV):

\subsection{Virulent NDV :}

Velogenic viscerotropic NDV (VVNDV) locally isolated strain (Sheble and Reda, 1967) of a titre $10^{8.5} \mathrm{EID} 50 / \mathrm{ml}$ was used for challenge test at a dose of $0.5 \mathrm{ml}$ containing $10^{5} \mathrm{EID} 50 / \mathrm{bird}$ via $\mathrm{I} / \mathrm{M}$ route.

\subsection{Live attenuated vaccinal NDV (HB1 strain):}

It was a commercial live vaccine supplied by Intervet Company, Lot No. 50046. The EID50 of this strain was $10^{9.7} / \mathrm{ml}$. It was used for the immunosuppression experiment.

\section{Cell cultures :}

3.1. Primary chicken embryo fibroblast cell culture (CEF) :

It was prepared according to Plowright and Ferris (1959) as modified by Osman et at. (1985).

\subsection{Cell lines :}

A. African green monkey kidney cell culture (VERO) :

VERO established by Yasumara and Kawatika (1963) were obtained kindly from NAMRU-3, Abbasia, Cairo.

B. Baby Hamster Kidney cell culture (BHK) :

$\mathrm{BHK}_{21}$ colon 13 grown as monolayer cultures were obtained also kindly from NAMRU-3.

3.3. Cell culture media :

Minimum Essential Medium (MEM), with Hank's salts (obtained from Gibco limited, P.O. Box 35, Paisley, Scotland) was prepared according to the manufacturer's instruction. It was supplemented with $10 \%$ new-born calf serum (obtained from Gibco) as growth medium at $\mathrm{pH}$ of 7.2.

4. Embryonated chicken eggs (ECE) :

Nine to ten day-old ECE were supplied by United Company Poultry Production were used for virus titration, SNT and preparation of primary CEF. 


\section{Serum samples :}

Serum samples were obtained from 4-5 weeks old chickens after 28 days of their inoculation intraocularly with $103 \mathrm{EID} 50 / \mathrm{ml}$ of clarified $10 \%$ $\mathrm{w} / \mathrm{v}$ bursal homogenate in addition to serum samples from non inoculated chickens as control samples. These samples were inactivated at $56^{0} \mathrm{C}$ for 30 minutes then kept at $-20^{\circ} \mathrm{C}$ until used as positive and negative antisera in SNT.

\section{Chickens :}

Three hundred, one to four weeks old, susceptible 320 chickens were obtained as one day old from UCPP and kept in isolated area until they subjected to different experiments.

\section{B. Methods :}

\section{Serum neutralization test (SNT) :}

It was carried out according to Jackwood et at. (1982) using the different cell cultures in the microtitre plates according to Rossiter et at. (1985).

\section{Virus titration :}

\subsection{Titration in ECE :}

The NDV and IBDV strains were titrated in 9 to 11 day old ECE. Such titration was done according to the method for examination of poultry biologies (1963). The EID50 was estimated according to Reed and Muench (1938).

\subsection{Titration in cell cultures :}

It was carried out using all prepared cell culture and ten dilutions of cell culture adapted IBDV in microtitre plates as described by Ferreira (1976). The virus titre was calculated according to Reed and Muench (1938).

\subsection{Growth curve of $\mathrm{IBDV}$ in cell cultures :}

The three used cell culture were grown in ordinary cell culture tubes. Each tube was inoculation with $0.1 \mathrm{ml}$ of the highest titre virus passaged, each in the corresponding cell culture. The virus was allowed to adsorb to the cells for 1 hour at $37^{0} \mathrm{C}$ then the non-adsorbed virus washed and discarded and each tube was supplied with $1 \mathrm{ml}$ of fresh maintenance MEM. On 0 hour then 6 hours intervals, 2 of these tubes were picked up and kept at $-70^{\circ} \mathrm{C}$ till the total virus yield was measured.

\section{Experimental design :}

Two experiments were done :
A. Experiment No. (1) :
Included two steps :

a. Trials to adapted the IBDV to cell culture: Three different cell culture 
were used (primary CEF, VERO and BHK) to choose the best one to adapted and replicate the virus with a high titre in a short time.

b. The use of this cell culture adapted IBDV in the routine SNT to evaluate the different strains of IBDV vaccines using the microneutralization test. In this experiment six different serotypes of IBDV vaccines from different commercial companies were used. They were designated as mentioned in material and methods. After ordinary vaccination of chickens for the routine evaluation of such vaccines, the immune response of vaccinated birds was compared using the method of inoculation in ECE and cell culture microneutralization test to choose the more sensitive, specific, less time consuming and economic method.

B. Experiment No. (2) :

Estimation of the immunogenicity of cell culture adapted IBD virus in chickens as a preliminary studies to be used in the production of cell culture IBDV vaccine and compared it with the available imported commercial egg adapted vaccines. Two steps were done :

a. -ria.s to cietermine the oest dose of vaccination anc compare between 2 cell origins of adaptation (VERO and BHK adapted IBDV); in this test 240 (4 weeks old) chickens were divided into 4 groups where groups 1 and 2 ( 80 birds / group), and vaccinated with different doses $(0.5,1.0,1.5$ and $2 \mathrm{ml}$ ) of both cell culture adapted IBDV individually via the drinking water. The two groups (groups 3 and 4) (40 birds / group) were kept as controls. Fifteen days post vaccination, serum samples were obtained from all groups then challenged except one group (group 4) kept as a negative control. Each bird was given one drop of virulent IBDV (local field isolate of $10^{3} \mathrm{EID} 50 / \mathrm{ml}$ ) via the eye. Serum samples were collected from all chickens after 15 days post vaccination and inactivated at $56^{\circ} \mathrm{C}$ for 30 minutes.

b. Trials to compare the immunogenicity and pathogenicity of IBDV adapted to the best cell culture of choice with the best dose, with the available commercial IBD vaccines. In this experiment 80 four-weeks old susceptible chickens were divided into 4 groups where group 1 and 2 ( 25 birds / group) were vaccinated with different 2 types of IBDV vaccines (cell culture adapted IBDV and live attenuated egg adapted commercial IBDV vaccine). These vaccines were given via drinking water where each vaccine was diluted to give $50 \mathrm{EID} 50$ or TCID50 per chicken. Before administration of the vaccines in drinking water, the chickens were deprived from water for 2 hours. The other 2 groups (15 birds / group) 
were kept as controls and all birds were observed for clinical signs of IBD and deaths attributable to vaccination. Five randomly selected birds from each vaccinated group were necropsied 7 days post vaccination in addition to 2 chickens from the control group. The bursae of these necropsied birds were examined for any lesions due to vaccination. The living vaccinated birds received live attenuated NDV (HB1) vaccine via the drinking water to check the immunosuppression effect. This vaccine was diluted to contain $10^{6.7}$ EID50 / dose. Three weeks post vaccination, all chicken groups were checked for the immune response and challenged at the same time with virulent IBDV and VVNDV where each bird was received one drop containing $10^{3} \mathrm{EID} 50 /$ dose via the eye route and 0.5 $\mathrm{ml}$ containing $10^{5}$ EID50/dose via I/M route; of VIBDV and VVNDV respectively. Deaths were recorded when they occurred. All survived chicken were necropsied and their bursae were examined for IBD lesions and trials of virus recovery from the organs of dead birds were done.

\section{RESULTS}

\section{Experiment (1) :}

Trials to adapted the IBDV on cell culture : Table (1) showed the comparison between the ability and sensitivity of the three used cell culture for propagation and replication of IBDV. After the first passage, the virus produced its CPE within 4, 7 and 9 days post inoculation in CEF, VERO and BHK cell cultures respectively recording a titre of $10^{2} \mathrm{TCID} 50 / \mathrm{ml}$. The virus began to increase logarithmically after several passages where its titre reached up to $10^{5}$ TCID50 $/ \mathrm{ml}$ after 10 passages when the CPE began to appear after 2, 3 and 2 days post inoculation in CEF, VERO and BHK respectively. The cell culture adapted IBDV lost its infectivity to the ECE at the passage No. 5 as after the No. 2, the EID50 was $10^{2.2} / 0.1 \mathrm{ml}$

Table (2) explained the growth curve of IBDV in both of CEF, VERO and BHK. Virus titration was done in each respective cell culture on 6 hours intervals. at 36 hours post-inoculation, the virus titre reached $10^{3}$ TCID $50 / \mathrm{ml}$ in the three cell cultures but it reached $10^{5} \mathrm{TCID} 50 / \mathrm{ml}$ after 60 hours in both CEF and BHK and after 72 hours post inoculation in VERO.

Table (3) showed the comparison between the level of the immune response in the sera of vaccinated chickens with the different IBDV vaccines, using both of the method of inoculation in ECE and microneutralization test. 
From this table, it was found that both methods were similar in indicating the neutralizing antibody as after 10 days from the first dose of vaccination with live attenuated IBDV (strain D78), the NI in egg inoculation method was ranging from 1.5 (in 5 samples) to 3.7 (in 1 sample). The same samples gave, using the microneutralization test; gave titres ranging from 1:4 (in 2 samples) to $1: 32$ (in one sample) while 5 samples showed 0 titre. Five days post the second vaccination, the table showed that the NI was ranging from 2.1 to 4 (in 3 samples out of 10) using ECE inoculation while in case of the use of micro-SNT, the same samples showed titres of 1:64 (in 4 samples out of 10). Thirteen days post the second vaccination, the NI using the egg inoculation method, was ranging from 1.5 (in 3 samples) to 3.2 (in 2 samples) and case of micro-SNT, the antibody titres were ranging from 1:4 to $1: 64$.

Also, the table showed the SNT titres in each sample 21 days post vaccination with the different inactivated commercial vaccines.

Fig. (1) showed the growth curve of IBDV in both of CEF, VERO and BHK.

\section{Experiment (2) :}

Table (4) revealed the best dose of choice for vaccination after inoculation of various doses of cell culture adapted IBDV in susceptible chickens. It was found that when the birds vaccinated with $1 \mathrm{ml}$ showed 100 $\%$ protection and a NI of 2.8 (arithmetic mean). The same protection $\%$ was obtained when the chickens were inoculated with a dose of 1.5 and $2 \mathrm{ml}$ of the vaccine while a dose of $0.5 \mathrm{ml}$ gave a protection of $80 \%$ with SNT titre of 2.0 (arithmetic mean).

Table (5) showed the comparison between the immunogenicity and pathogenicity of both live attenuated cell culture adapted IBDV and available live attenuated egg adapted IBDV vaccine. The immune response of vaccinated chicken was determined by challenging birds with a known virulent IBDV and VVNDV and by measuring the serum neutralizing antibody titres, 21 days post vaccination in addition to the body weight loss and bursal lesions records. The table revealed that there were no bursal lesions observed at 7 days post inoculation with both vaccines. The SN antibody titre at 21 days post vaccination was ranging from 1:4 to $1 ; 128$ in the chickens vaccinated with cell culture adapted vaccine while it ranged from 1:4 to $1: 64$ in the other group. The protection \% was 90 and 85 in groups 1 and 2 respectively after challenge with virulent IBDV. The vaccinated chickens showed no bursal lesions after challenge, while in case of control birds, the bursae were enlarged oedematous and yellowish in colour 
and the IBDV was recovered from them. Also, the results of this experiment showed that there was no any immunosuppression as the vaccinated chickens in both groups had 90 to $85 \%$ protection respectively after challenged with virulent VVNDV while the control birds showed nervous manifestation before death and NDV was recovered from the infected organs.

\section{DISCUSSION}

Lukert et at. (1975) adapted the IBDV to cell cultures as the vaccine virus presently used in the United States, for the control of IBD, is not completely attenuated and produced some mortalities.

Propagation of infectious bursal disease virus (IBDV) in chicken embryos has been described by various investigators (Hitchner, 1970 and Winterfield et at., 1972).

Several workers have reported on the propagation of IBDV in different cell cultures prepared from chickens or chicken embryo (Kosters anc Pau.sen, :97:; Mora, -966 ancं -uxert et at., :975) in tria.s to adaptec. the virus to cell cultures and detect the pathogenicity and immunogenicity of such adapted virus in chickens in order to overcome the incomplete attenuated vaccines that used foe controlled exposure of flocks with enzootic IBD.

Propagation of IBDV in continuous cell lines originated from African green monkey kidney (VERO) was reported by Lukert et at. (1975). Hirai and Caluck (1979) propagated the virus in bursa (B-cells) derived lymphoblastoid cell line with maximum virus yield obtained 3 days post inoculation.

This study was done to find an alternative to embryonated chicken egg (ECE) inoculation that could be used in routine SNT or IBDV antibody. The use of a cell culture, specially a continuous cell line, has several advantages over the use of primary cell cultures. Maintaining a continuous cell line is more cost effective than propagating CEF from SPF chicken embryos. The primary cell cultures have an end life span in vitro, while the continuous cell lines can be cultured without end. Also, the primary avian cell cultures may contain extraneous avian viruses not found in mammalian cell cultures.

Our results indicated that IBDV replicated and produced CPE in the two cell lines (VERO and BHK) used in this study similar to that produced in $\mathrm{CEF}$ cell cultures. Although, the CEF seem to produce CPE faster than the 
cell lines but there was no difference in their sensitivity. As after the first passage, the onset of CPE began to appear at 4, 7 and 9 days post inoculation in CEF, VERO and BHK, respectively and took at least 9 days in the three cell cultures and the titre was $10^{2}$ TCID50/0.1 ml. After 8 passages, the onset of CPE began to produce at 2 days PI in both CEF and BHK and continued for 3 and 4 days respectively where its titre reached $10^{5}$ TCID50 / $0.1 \mathrm{ml}$, while in case of VERO cells, the CPE appeared after 3 days and lasted for 4 days showing a titre of $10^{5}$ TCID $50 / 0.1 \mathrm{ml}$ (table 1 ). So, our results agreed with Lukert et at. (1975) as they found that the titre of IBDV in VERO cells during the first passages was $10^{3} \mathrm{PFU} / \mathrm{ml}$ at 3 days and $10^{5.3} \mathrm{PFU} / \mathrm{ml}$ at 7 days. Also, they found that the plaques not produced in VERO cells until the fourth passage and took 13 days to become visible. After 8 passages in VERO cells; plaques developed 7 days PI.

The growth curve of IBDV in the three used cell cultures, indicated that the virus growth curve was similar in both of CEF and BHK, although the peak titre was reached to its plateau after 54 hours PI in case of BHK after 60 hours PI in case of CEF as the titre was $10^{5}$ TCID50/0.1 ml in case of VERO cells, the peak titre reached after 66 hours PI (table 2 and Fig. 1).

Dehorah et at. (1987) used three mammalian continuous cell lines (MA, 104, VERO and BGM-70). The results indicated that IBDV produced $\mathrm{CPE}$ in the first passage in BGM-70 cells, by 72 hours PI. The CPE of the virus in these cells was similar to that in CEF. The peak titre of IBDV in CEF was detected at 40 hours PI. The quantity of IBDV in BGM-70 reached a plateau at approximately 54 hours PI.

IBDV adapted to BHK cells was used for additional studies as the CPE produced at 54 hours PI with a titre of $10^{5}$ TCID50/0.1 ml (table 2).

The antibody titres obtained by using both of inoculation in ECE and microneutralization test, indicated that SNT in cell cultures was similar in sensitivity and specificity as ECE, but SNT in cell cultures is more economic where it does not need large numbers of eggs in addition to the fact that a large number of samples can be screened for antibodies, so, it is less in time consuming.

According to the results obtained in this study, it was concluded that the cell lines can be used in place of ECE and CEF cell cultures for the purpose of SNT. Our results agreed with Dehorahg et at. (1987) who found that virus neutralization test in CEF and BGM-70 cell cultures produced comparable results. 
The objective of the second experiment is a trial to determine the immunogenicity and pathogenicity of cell culture adapted IBDV when used as a vaccinal strain for chickens.

Our results showed that the best dose that gave a $100 \%$ protection after challenge of vaccinated birds with virulent IBDV, was $1 \mathrm{ml}$ via drinking water where the arithmetic mean of NI at 15 days post inoculation with $1 \mathrm{ml}$ of cell culture adapted IBDV on both VERO and BHK via drinking water, was 2.5 and 2.8 respectively. While, $0.5 \mathrm{ml}$ gave a $80 \%$ protection (Table 4). El-Ibiary et at. (1992) found that the protection rate is proportional to the amount of introduced antigen. To produce an efficient immunity level, a full dose of live vaccine $(1 \mathrm{ml})$ should be given orally.

Lukert et at. (1975) proved that the VERO cell adapted IBDV was completely attenuated and effective as a vaccine when given subcutaneously and not effective when administrated via the drinking water. Bur the chicken kidney cell culture adapted virus could be administrated in drinking water without mortalities or body weight loss following vaccination.

Our results indicated that the BHK cell culture adapted IBDV could be used as a vaccine. Table (5) showed that there was no any bursal lesions 7 days post vaccination and there was no mortality or loss in body weight during the observation period. The vaccinated birds showed SN antibody titre ranging from $1: 4$ to $1: 128$ as 8 chickens out of 20 , gave a titre of $1: 128$; 4 birds gave 1:64 and 5 birds gave 1:16 SNT, while the vaccinated chickens with the live attenuated commercial IBD vaccine gave SNT titre from 1:2 to $1: 64,21$ days post vaccination. The protection $\%$ after challenge with virulent IBDV was $90 \%$ in vaccinated chickens with cell culture adapted IBDV and $85 \%$ with commercial IBD vaccine (Table 5). The results indicated that the cell culture adapted IBDV can be used safely as it had no any immunosuppressive effect where the protection $\%$ after the challenge with VVNDV was 905 and 855 in both of group 1 and 2 .

Skeels et at. (1979) found that the virus was not detected in tissues of birds given the cell culture adapted IBDV at 3 weeks of age.

From the previous results, it was concluded that the continuous cell lines can be used in place of primary CEF and egg inoculation method in the purpose of SNT. Also, the BHK cell adapted IBDV was effective and safely used as a vaccine. 


\section{REFERENCES}

Benton, W.J.; Cover, M.S. and Rosenberger, J.K. (1967): Studies on the pathogenicity of Gumboro disease in the bursa of Fabricius, spleen and thymus of chicken. Am. J. Path., 51: 527 - 551.

Deborah, H.; Jackwood, D.J.; Saif, Y.M. and Hughes, J.H (1987):

Replication of infectious bursal disease virus in continuous cell lines.

Avian diseases, 31 (2) : 370 - 375.

El-Ibiary, E.A.; Hussein, N.A. and El-Nimr, M.H. (1992): Effect of infectious bursal disease vaccinal doses on immunity gained by chickens. Beni-Suef Vet. Med. Ass., 2 : 55 - 67.

Ferreira, M.E. (1976): Pruba de microneutralization proestudos de anticrupos de la fiebre aftose. Blin. Centopano Americano de F. Ubrea, $211: 17$ - 27.

Gelenczei, E.F. and Juniger, P.D. (1970): Isolation of reovirus from bursa of Fabricius of chickens affected by innfectious bursal disease. J.A.V.M.A., $156: 1270$ - 1271.

Hiari, K. and Calnek, B.W. (1979): In vitro replication of infectious bursal disease virus in established lymphoid cell lines and chicken Blymphocytes. Infect. Immunol., $25: 964$ - 970.

Hitchner, S.B. (1970): Infectivity of infectious bursal disease virus for embryonated eggs. Poult. Sci., 49 : 511 - 516.

Jackwood, D.J.; Saif, Y.M.; Moorhead, P.D. and Dearth, R.N. (1982):

Infectious bursal disease virus and alcaligenes faecalis infections in turkeys. Avian Dis., 26 : 365 - 374.

Koster, J. and Paulsen, J. (1971): Vermhrung des erregers infectioosen bursitis des Jumghennen in Huhner embryonieren zell kultur. Zentbl. Vet. Med., $188: 366$ - 372.

Koster, J.; Becht, H. and Rudolph, R. (1972) : Properties of the infectious bursal agent of chicken (IBA). Med. Microbiol. Immun., $157: 291$ 298.

Lukert, P.D. and Davis, R.B. (1974): Infectious bursal disease virus : growth and characterization in cell culture. Avian Dis., $18: 243-250$.

Lukert, P.D.; Leonard, J. and Davis, R.B. (1975): Infectious bursal disease: antigen production and immunity. Am. J. Vet. Res., $36: 539-540$.

Marquardt, R.B. Johnsonn; Odeuwald, W.F.and Schlotthober, B.A. (1963): Avian Dis., 24 (2) : 375 - 385. 
McNulty, M.S.; Allan, G.M. and McFerran, J.B. (1979): Inoculation of infectious bursal disease virus from turkeys. Avian Pathol., $8: 205$ 212.

Methods for Examination of Poultry Biologies (1963): National Academy of Science, National Research Concil, Washington, D.C.

Mora, E.C. (1966): Virus infections of cultured macrophages on lymphocytes. Poult. Sci., 45 : 1106 - 1107.

Osman, O.A.; Mouaz, M.A.; Athnasius, S. and AbdEl-Ghafar, S. (1985): Comparative studies on in-vitro and in-vivo titration of pooled batches of cell culture rinderpest vaccine. Al-Azhar J. Pharm. Sci., Sept. $4: 87-93$.

Petek, M. and Mandettl, G. (1968): Proprieta biologichedium reovirus isolato da un facalaio di malattia Gomboro. Atti. Soci. Ilal. Sci. Vet., 22 : 875 - 879.

Petek, M.; D'Aprile, P.N. and Cancelloti, F. (1973): Biological and physicochemical properties of the infectious bursal disease virus (IBDV). Avian Pathol., 2 : 135 - 152.

Plowright, W. and Ferris, R.D. (1959): Studies on rinderpest virus in tissue culture. 1. Growth and cytopathogenicity. J. Comp. Pathol., 29 : 152.

Reed, L.J. and Muench, H. (1938): A simple method for estimation of $50 \%$ end point. Am. J. Hyg., $77: 493$ - 494.

Rinaldi, A.; Lodetti, E.; Cessi, D.; Lodrini, E.; Gervio, G. and Nardelli, L. (1972): Coltura del virus de Gumboro (IBA) su fibroblest di embrioni di pollo. Nouva Vet., 48 : 195 - 201.

Rossiter, P.B.; Jesset, D.M. and Taylor, W.P. (1985): Microneutralization system for use with different strains of peste des petits ruminants and rinderpest viruses. Trop, An. Heal Prod., 17 (2) : 75 - 81.

Skeels, J.K.; Lukert, P.D.; Fletcher, O.J. and Leounard, J.D. (1979):Immunization studies with a cell culture adapted bursal disease virus. Avian Dis., 23 : 456 - 465.

Winterfield, R.W. (1969): Immunity response to the infectious bursal disease agent. Avian Dis., 13 : 548 - 557.

Winterfield, R.D.; Fadly, A.M. and Bickford, A. (1972): Infectivity and distribution of infectious bursal disease in chicken : persistence of the virus and lesions. Avian Dis., $16: 622$ - 632.

Yasumara, Y. and Kawatika, Y. (1963): Studies on SV40 virus in tissue culture. Nihon Rinsho, $21: 1201$ - 1215. 
Table (1):Comparison between the onset of the cytopathic effect (CPE) of IBDV in different cell cultures.

\section{Type of cell culture}

Passage, No.

$\begin{array}{lll}\text { CEF VERO BHK } & \text { ECG }\end{array}$

On.CPE T.H Ti. On.CPE T.H. Ti. ON.CPE T.H. Ti Ti.

$\begin{array}{lrrrrrrrrrr}1- & 4 & 9 & 2 & 7 & 9 & 2 & 9 & 10 & 2 & 7 \\ 2- & 4 & 9 & 2 & 6 & 8 & 2 & 8 & 9 & 3 & 6 \\ 3- & 3 & 6 & 3 & 6 & 7 & 3 & 8 & 9 & 3 & 3 \\ 4- & 3 & 5 & 3 & 5 & 7 & 3 & 5 & 6 & 3 & 2 \\ 5- & 3 & 5 & 4 & 3 & 4 & 3 & 5 & 6 & 4 & 0 \\ 6- & 2 & 5 & 4 & 3 & 4 & 4 & 4 & 6 & 5 & 0 \\ 7- & 2 & 4 & 4 & 3 & 4 & 4 & 3 & 5 & 5 & 0 \\ 8- & 2 & 3 & 5 & 3 & 4 & 5 & 2 & 4 & 5 & 0 \\ 9- & 2 & 3 & 5 & 3 & 4 & 5 & 2 & 3 & 5 & 0 \\ 10- & 2 & 3 & 5 & 3 & 4 & 5 & 2 & 3 & 5 & 0\end{array}$

*On.CPE = Onset of CPE in days post inoculation.

**T.H. = Time of harvestation in days post inoculation.

${ }^{* * *} T \mathrm{Ti} .=$ Titre $(\log 10) .\left\{T_{C} I_{50}\right.$ in case of cell cultures and EID 50 in case of ECG 
Assiut Vet. Med. J. Vol. 36 No. 72, January 1997

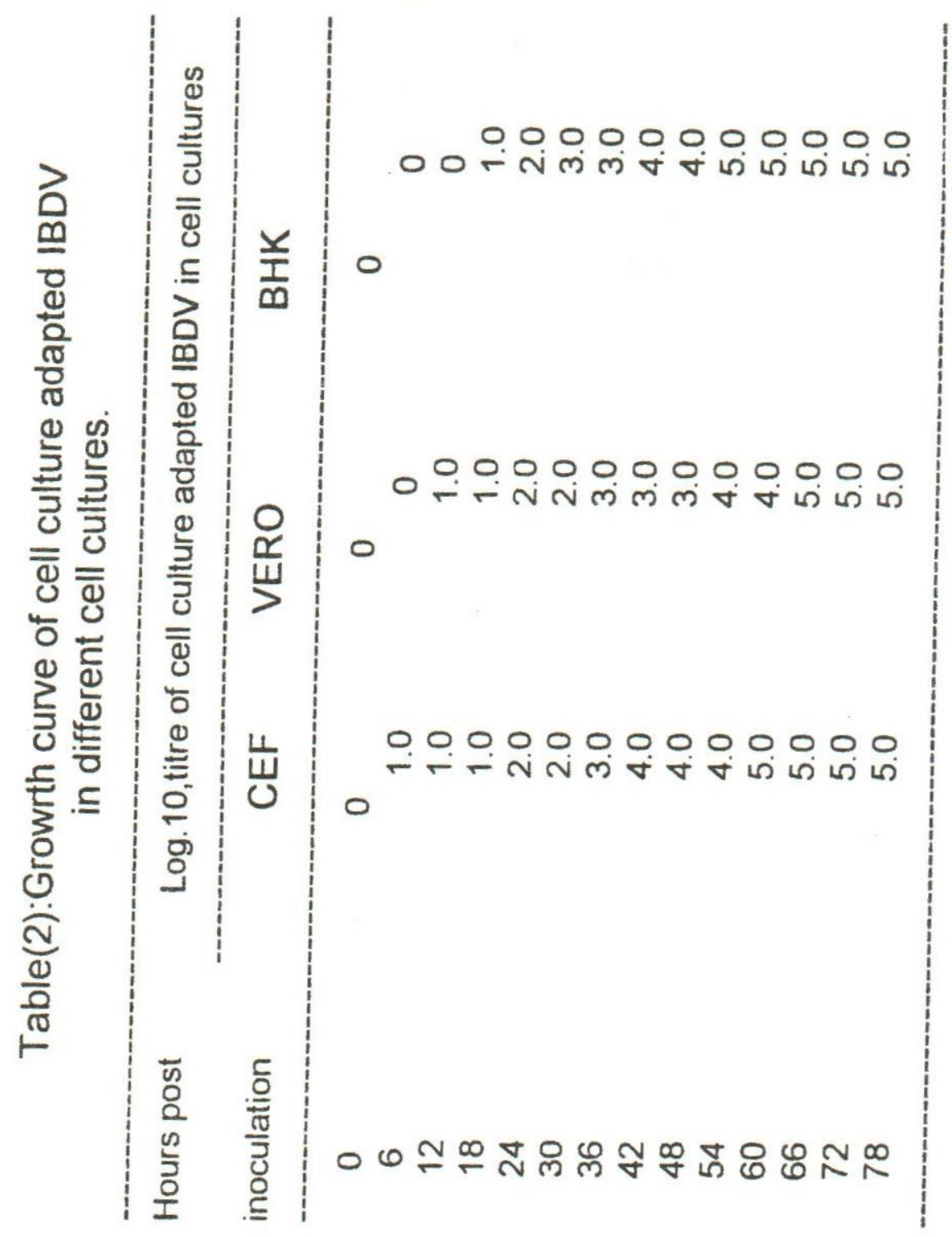


Table (3) : Comparison between the neutralizing antibody titre ir vaccinated chickens using microneutralization test and egg inoculation method.

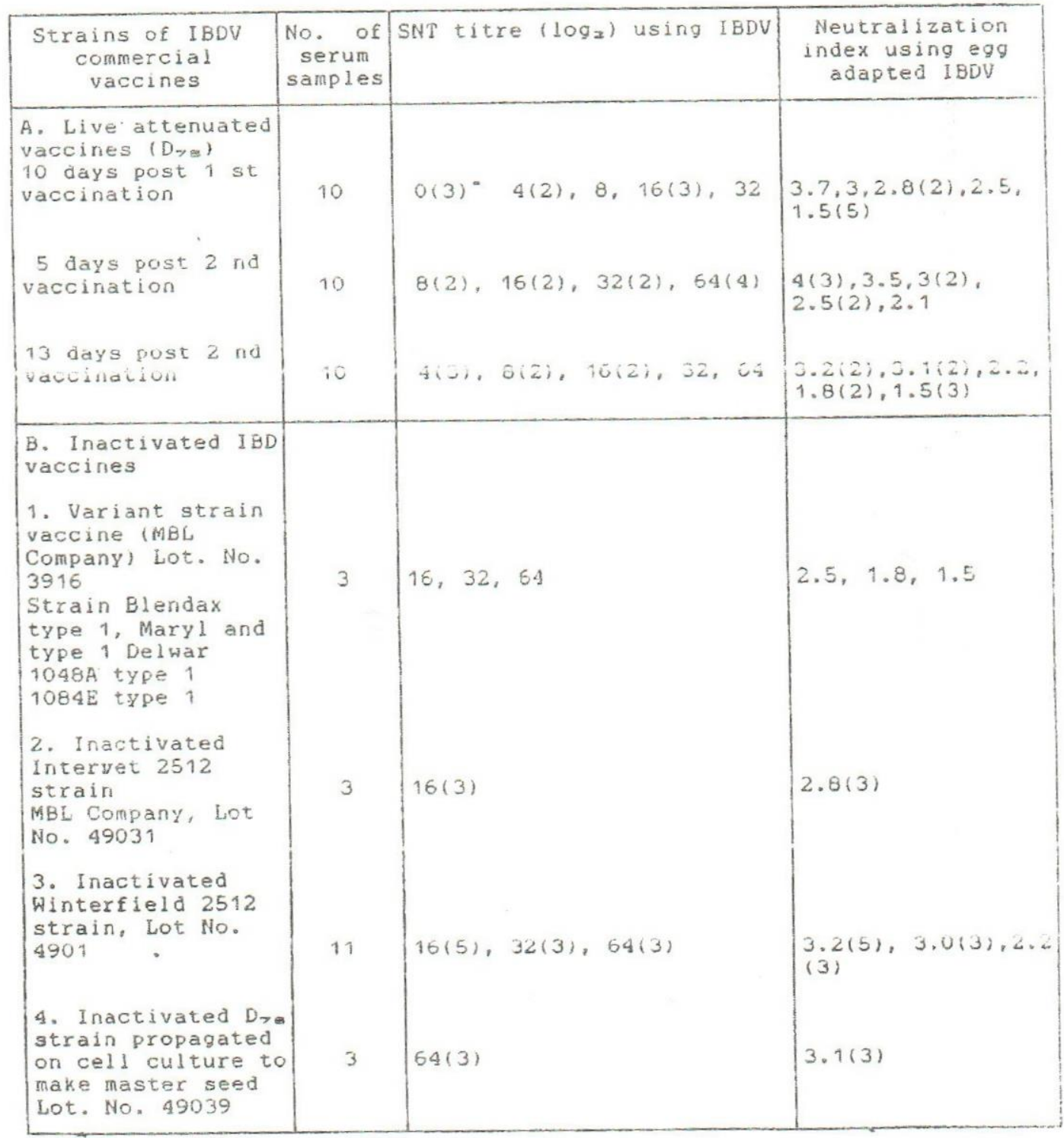

( ) : Number of positive samples. 


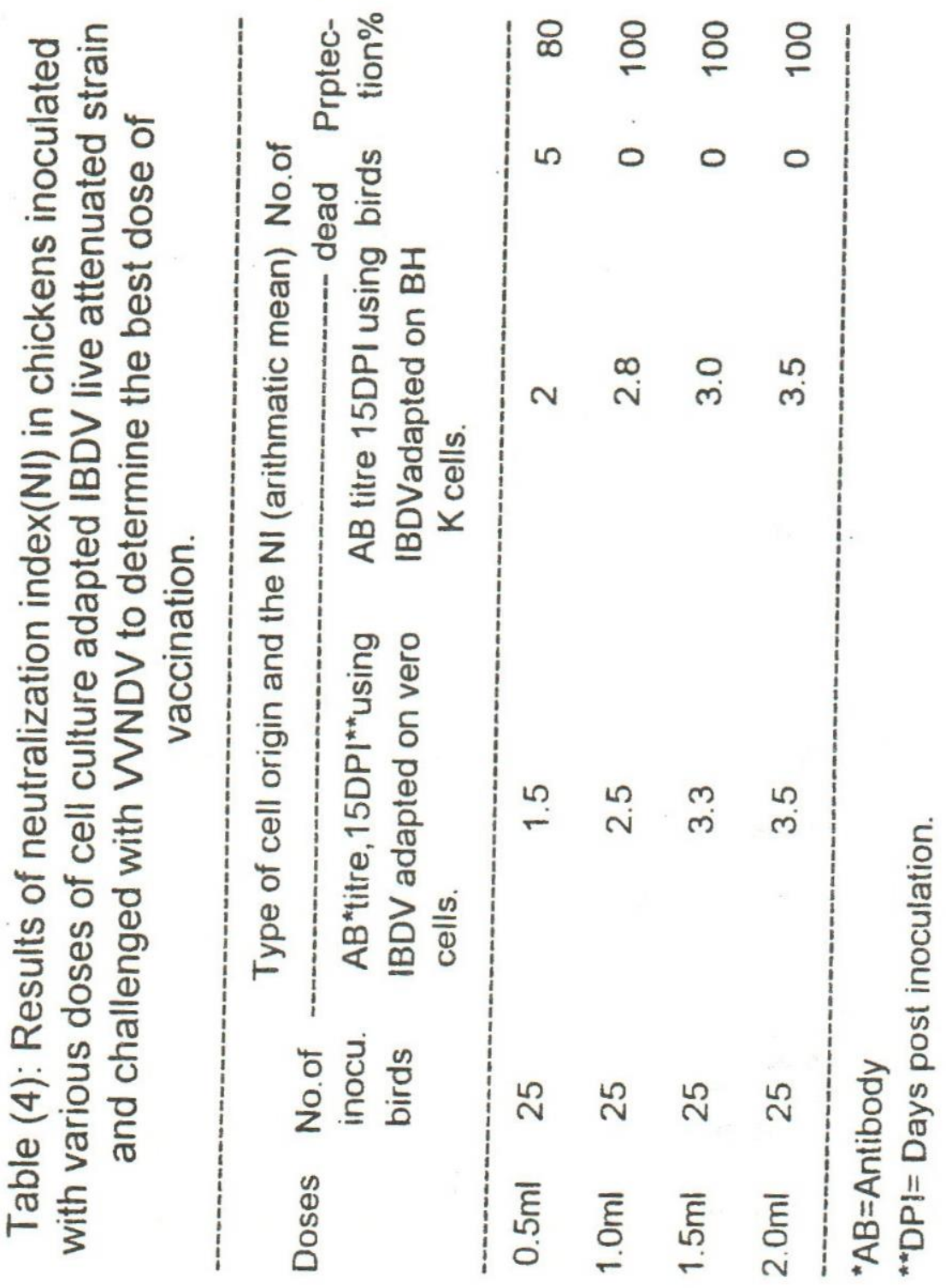


Table (5): Comparison between the immunogenicity and pathogenicity of IBDV adapted to BHK cells and available commercial live attenuated IBDV vaccine.

Post vaccinal Type of virus Route of Days post No.of Gp.1 Gp.2 Con.gp. reactions

$$
\text { Strain }
$$

Inocu 1 vaccinatio- birds

n.

-Bursal lesions

-Mortality

-Weight loss

-Immuno-supp-

ression test: $\quad H B_{1}$

-SNT titre for

IBDV

-Challenge

reaction:

Protection \% IBDV

Bursal lesions drinking

water

drinking
water

$7 \quad 20 / G p$

21 post IBDV

eye drops 10
post
challe-
nge.
10 dpc.

7

$$
\text { -ve -ve }
$$

-ve

$$
\text { 5/Gp. -ve -ve -ve }
$$

$$
\text { -ve -ve -ve }
$$




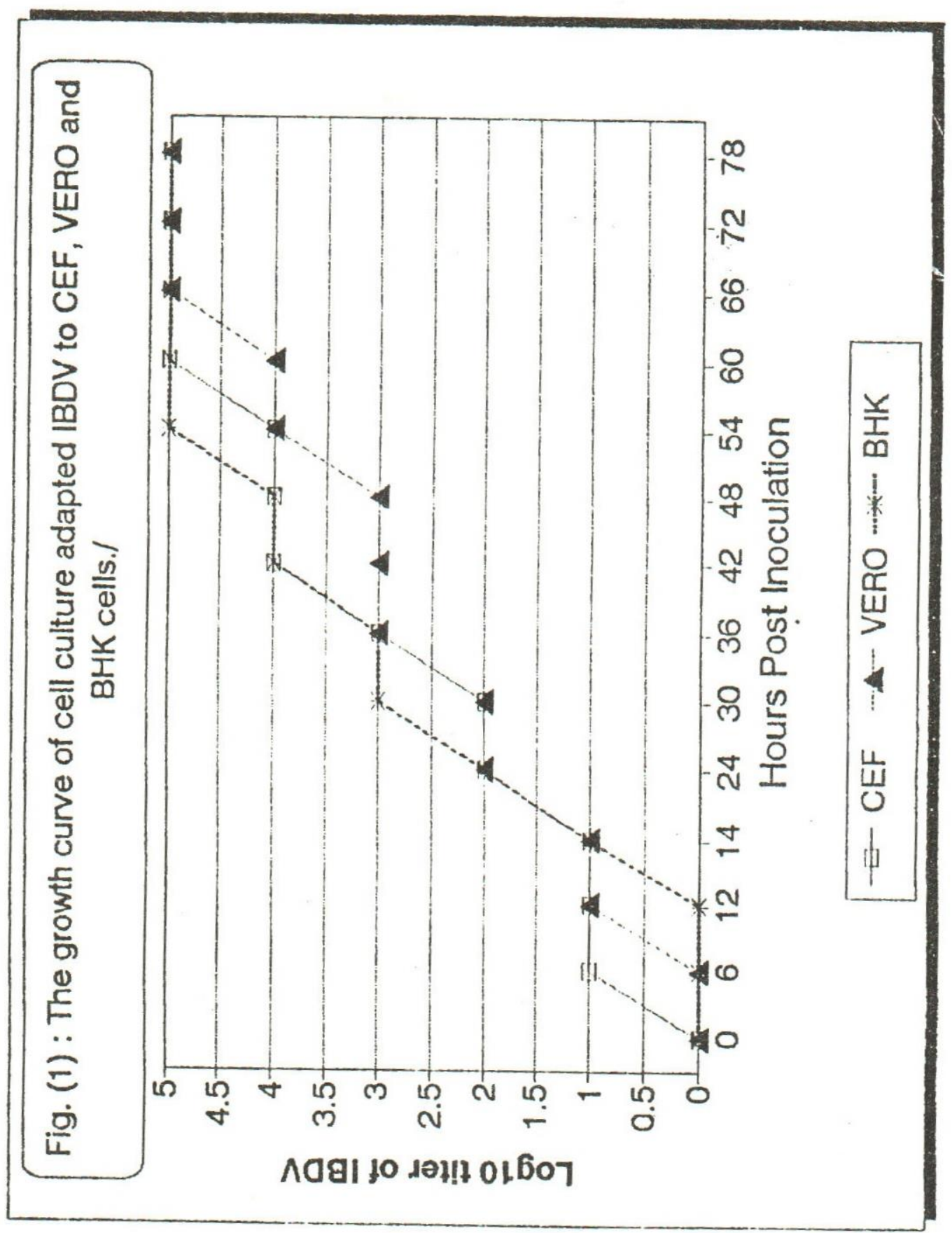


